\title{
Systemic Lupus Erythematosus Presenting As Cryptogenic Organizing Pneumonia: Case Report
}

\author{
Anthony Jedd, MD \\ Sashank Kolli, MD \\ Thomas Liao, MD \\ Isabel Oliva, MD \\ Loyola University Of Chicago \\ Stritch School Of Medicine \\ Maywood, IL \\ and \\ University of Arizona \\ Tucson, AZ
}

\section{Introduction}

Systemic Lupus Erythematosus (SLE) is a systemic disease with multiorgan involvement. In the respiratory system, SLE can involve the lung parenchyma and pleura with intrathoracic manifestations of pleuritis, alveolar hemorrhage and pulmonary fibrosis. Cryptogenic organizing pneumonia (COP) is a rare complication of SLE. We describe a case of newly diagnosed lupus presenting as COP.

\section{Case Report}

An 18-year-old woman with no significant past medical history presented to the Emergency Department complaining of generalized malaise, cough and fever for 4 days. Her cough was productive with white to brownish sputum. She complained of chest heaviness/pressure with inability to take deep breaths. Her only reported sick contact was her mother who had the "flu" one week prior to the onset of her illness. She denied any illicit drug use, alcohol or smoking, as well as any recent travel or exotic pet exposure. On admission, her vital signs were: temperature $38.4^{\circ} \mathrm{C}$, pulse rate $129 \mathrm{bpm}$, blood pressure 159/108 $\mathrm{mmHg}$, respiratory rate $29 \mathrm{rpm}$ and oxygen saturation $94 \%$ on room air. On physical exam, the patient was in moderate distress with tenderness to palpation over her muscles. Left anterior cervical adenopathy was present and lung auscultation revealed coarse bilateral crackles. She was alert and oriented times 3 with no neurological deficits.

Laboratory data on admission: white blood cell count $5100 / \mu \mathrm{L}$ with $43 \%$ bands, hemoglobin $10.6 \mathrm{~g} / \mathrm{dL}$, platelets $125 \times 10^{9} / \mathrm{L}$, blood urea nitrogen $37 \mathrm{mg} / \mathrm{dL}$, and creatinine $2.0 \mathrm{mg} / \mathrm{dL}$. Urinalysis revealed a large amount of microscopic blood, small amount of leukocyte esterase, moderate bacteria and protein $>300 \mathrm{mg} / \mathrm{dl}$. ABG of pH $7.39 / \mathrm{pCO} 228 \mathrm{~mm} \mathrm{Hg} / \mathrm{pO} 2$ of $68 \mathrm{~mm} \mathrm{Hg}$ on 2L/min by nasal cannula. Initial chest radiograph (CXR) demonstrated bilateral perihilar infiltrates (Figure 1). 


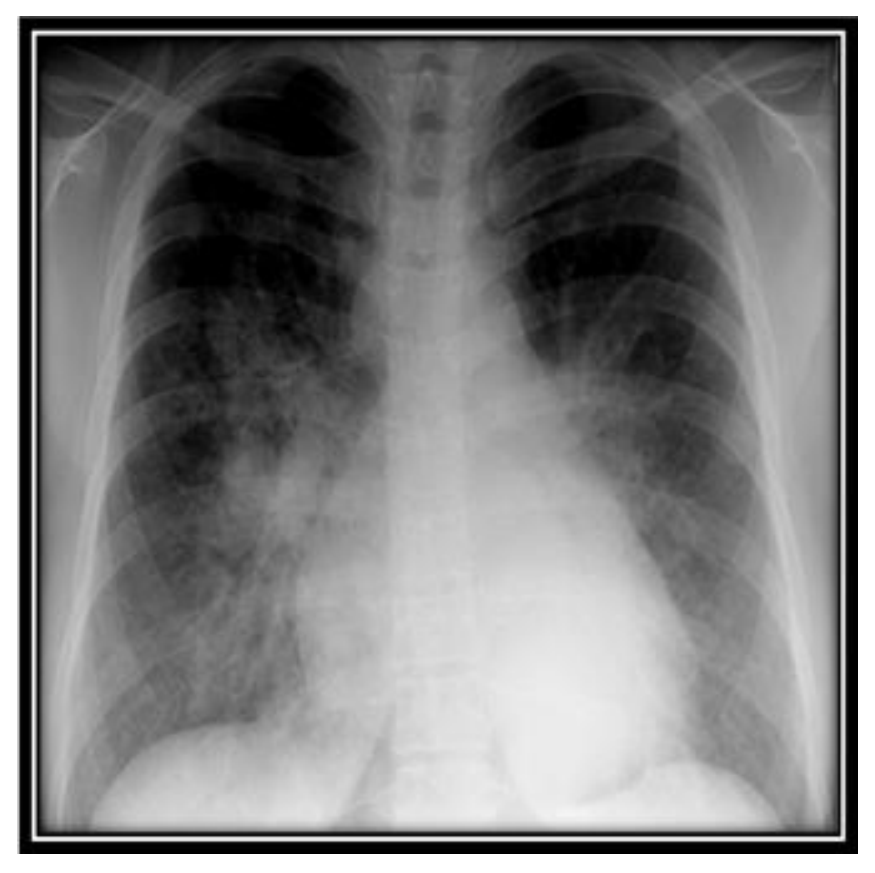

Figure 1. CXR on admission.

She was started on ceftriaxone and azithromycin with a working diagnosis of sepsis secondary to community-acquired pneumonia with impending respiratory failure.

She continued to be febrile, hypoxic and tachycardic. A 4-day follow-up CXR demonstrated interval worsening of bilateral airspace disease (Figure 2).

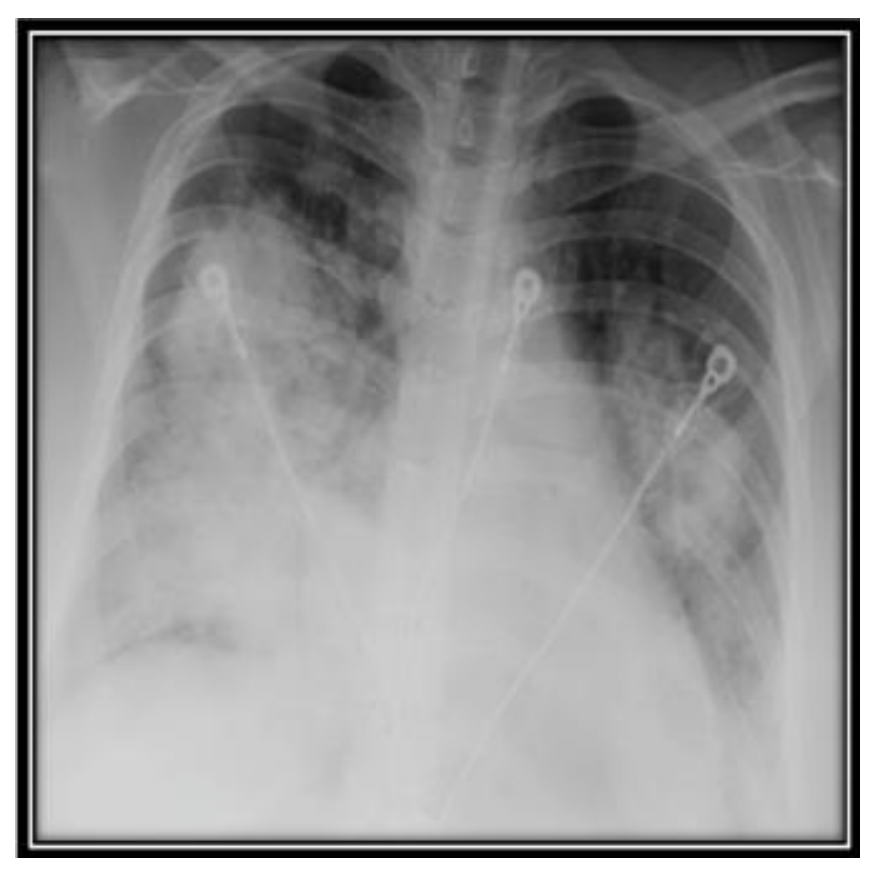

Figure 2. CXR on hospital day 4. 
Despite antibiotic therapy for 5 days she was intubated due to continued deterioration. Diagnostic bronchoscopy was performed showing a positive mycoplasma IgM, while samples for bacterial, viral and fungal sources as well blood cultures were negative. GMS stain for Pneumocystis was also negative. At this time infectious disease recommended switching the antibiotics to vancomycin and aztreonam.

The patient continued to have persistent anemia, thrombocytopenia and urine containing large amounts of protein raising suspicion for an autoimmune hemolytic anemia with bone marrow failure. Rheumatologic panel revealed ANA titer of 2,560 (normal $<40$ ), anti-ds DNA antibody $>300 \mathrm{IU} / \mathrm{ml}$ (normal $<10$ ) and normal complement C3,C4. HIV testing was non reactive. Per rheumatology's recommendations, she was started on methylprednisolone $1 \mathrm{~g}$ daily for 3 days and later switched to prednisone 100 $\mathrm{mg}$ daily and $600 \mathrm{mg}$ cytoxan for the working diagnosis of systemic lupus erythematosus (SLE). After about 1 week of persistent extensive bilateral lung infiltrates and continued ventilator dependence, an open lung biopsy was performed which demonstrated bronchoalveolar tissue showing organizing pneumonia of unknown etiology (Figure 3). No histological findings for vasculitis or alveolar hemorrhage were identified.

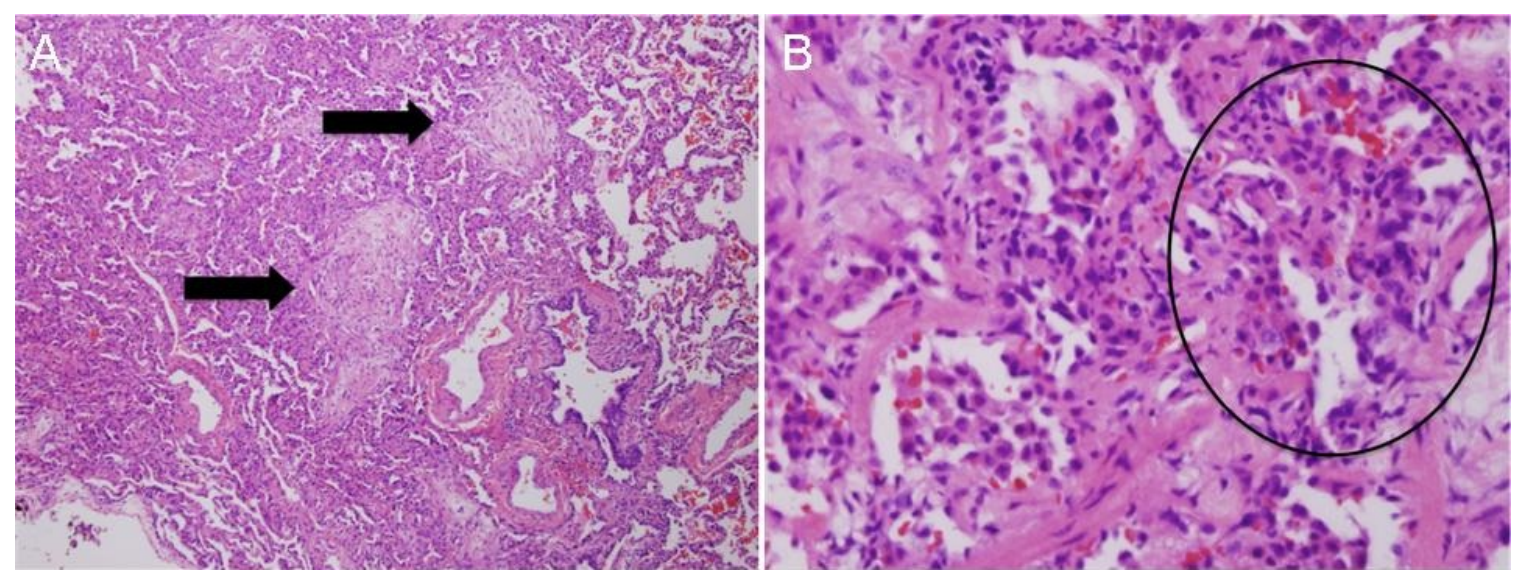

Figure 3. Panel A: patchy fibroblastic plugs in bronchioles and alveolar ducts (bronchiolitis obliterans) (black arrows). Panel B: Organizing pneumonia within alveoli (black circle).

She was diagnosed with SLE involving multiple organs, which included lung, kidneys and bone marrow. Prednisone $100 \mathrm{mg}$ daily was continued for 2 weeks. Broad spectrum antibiotics were discontinued, but she finished a 2 week coarse of azithromycin for the positive mycoplasma antibodies. Her respiratory status gradually improved and she was extubated on her 14th hospital day. As an outpatient, prednisone was tapered slowly over the next 2 months to $10 \mathrm{mg}$ daily and then she was transitioned to mycophenolate. Follow-up CXR showed resolution of the airspace disease (Figure 4). 


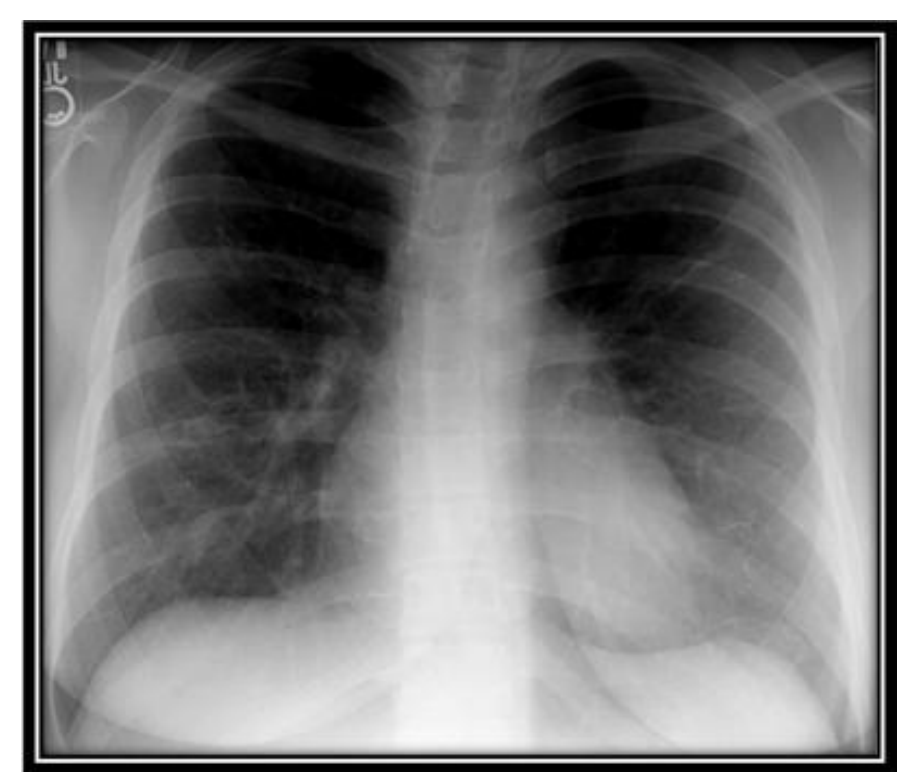

Figure 4. CXR 2 months after admission to ICU.

\section{Discussion}

Cryptogenic organizing pneumonia is a noninfectious inflammatory pulmonary process that leads to the formation of fibromyxoid connective tissue plugs that adhere to the walls of the alveolar ducts and alveoli $(1,2,4)$. COP can be idiopathic or secondary to several etiologies, including drug toxicity, infection, connective tissue diseases (CTD), malignancy and bone marrow transplantation (6). The diagnosis of SLE-related COP is rare with no cohort studies showing a dominant type of CTD resulting in COP.

Oymak S et al. (8) reviewed etiologic and clinical features in 26 patients with COP and found that $58 \%$ were idiopathic. The other $42 \%$ were secondary, but the causes were not described. Yoo JW et al. (9) further compared cryptogenic organizing pneumonia and connective tissue disease-related organizing pneumonia (CTD-OP). The study showed rheumatoid arthritis, Sjogren's syndrome and polymyositis/dermatomyositis were predominant types of CTD and no patients were mentioned with SLE (9). Other studies mention polymyalgia rheumatica and SLE as potential causes of COP, but there are no reported cases of the two entities presenting together in adults (10-12).

The mechanism by which SLE can lead to the development of COP is unknown. Otsuka et al. (13) suggested that elevated antiphospholipid antibodies contribute to the development of Masson bodies, macrophages and fibrin found within pulmonary alveoli, due to an inhibited inflammatory repair mechanism within the airways, which may contribute to the development of COP. The hypothesis of epithelial damage by the immune system is supported by the response to steroid therapy, which prevents and/or resolves deposition of IgM, IgG and infiltration of plasma cells into the bronchiolar walls $(14,15)$. 
The development of SLE-related COP remains a rare entity. Our patient's presentation was unique in that COP was the initial manifestation of her SLE. Additionally, the pattern of airspace disease on chest radiograph was atypical for organizing pneumonia, which usually presents as either peripheral or peribronchiolar areas of consolidation. As more cases arise, our understanding of the mechanism and timing of the disease will hopefully become more apparent.

\section{References}

1. Epler GR, Colby TV, McLoud TC, Carrigton CB, Gaensler EA. Bronchiolitis obliterans organizing pneumonia. N Engl J Med 1985;312:152-8. [CrossRef] [PubMed]

2. Colby TV. Pathologic aspects of bronchiolitis obliterans organizing pneumonia. Chest 1992;102:38S-43S. [CrossRef] [PubMed]

3. Epler GR. Bronchiolitis obliterans organizing pneumonia. Arch Intern Med. 2001;161:158-64. [CrossRef] [PubMed]

4. Moore SL. Bronchiolitis obliterans organzining pneumonia: a late complication of stem cell transplantation. Clin J Oncol Nurs. 2003;7(6):659-62. [CrossRef] [PubMed]

5. Cordier JF. Organizing pneumonia. Thorax 2000;55:318-28. [CrossRef] [PubMed]

6. Roberton B, Hansell D. Organizing pneumonia: a Kaleidoscope of concepts and morphologies. Eur Radiol 2011;21:2244-54. [CrossRef] [PubMed]

7. Takada H, Saito Y, Nomura A, Ohga S, Kuwano K, Nakashima N, Aishima S, Tsuru $\mathrm{N}$, Hara $\mathrm{T}$. Bronchiolitis obliterans organizing pneumonia as an initial manifestation in systemic lupus erythematosus. Pediatr Pulmonol. 2005;40:257-260. [CrossRef] [PubMed]

8. Oymak S, Demirbas HM. Mavili E, Akgun H, Gulmex I, Demir R, Ozesmi M. Bronchiolitis obliterans organizing pneumonia. Respiration. 2005;72:254-62. [CrossRef] [PubMed]

9. Yoo JW, Song JW, Jang SJ, Lee CK, Kim MY, Lee HK, Jegal Y, Kim DS. Comparison between cryptogenic organizing pneumonia and connective tissue disease-related organizing pneumonia. Rheumatology 2011;50:932-8. [CrossRef] [PubMed]

10. Douglas WW, Tazelaar HD, Hartman TE, Hartman RP, Decker PA, Schroeder DR, Ryu JH. Polymyositis-dermatomyositis-associated interstitial lung disease. Am J Respir Crit Care Med. 2001;164(7):1182-5. [CrossRef] [PubMed]

11. Katzenstein ALA, Myers J, Prophet WD, Corley LS 3rd, Shin MS. Bronchiolitis obliterans and usual interstitial pneumonia. Am J Surg Pathol. 1986;10:373-81. [CrossRef] [PubMed]

12. Lynch D. Lung disease related to collagen vascular disease. J Thorac Imaging. 2009;24(4):299-309. [CrossRef] [PubMed]

13. Otsuka F, Amano T, Hashimoto N, Takahashi M, Hayakawa N, Makino H, OtaZ, Ogura T. Bronchiolitis obliterans organizing pneumonia associated with systemic lupus erythematosus with antiphopholipid antibody. Intern Med. 1996;35:341-4. [CrossRef] [PubMed] 
14. Myers JL, Katzenstein AL. Ultrastructural evidence of alveolar epithelial injury in idiopathic bronchiolitis obliterans-organizing pneumonia. Am J Pathol. 1988;132(1):102-9. [PubMed]

15. Ippolito JA, Palmer L, Spector S, Kane PB, Goveric PD. Bronchiolitis obliterans organizing pneumonia and rheumatoid arthritis. Semin Arthritis Rheum. 1993;23(1):70-8. [CrossRef] [PubMed] 